\title{
Práticas de ensino e aprendizagem de matemática e tecnologia: um olhar para as especificidades da educação de jovens e adultos (EJA)
}

\author{
Mathematics and technology teaching and learning practices: A look at the \\ specificities of the Adult Basic Education (ABE)
}

\author{
Bruno Tizzo Borba ${ }^{1}$ \\ Maria Teresa Menezes Freitas ${ }^{2}$
}

\section{Resumo}

Este produto de mestrado, refere-se a uma pesquisa, que buscou-se averiguar as potencialidades das tecnologias, em especial as Tecnologias da Informação e Comunicação (TICs), no processo de aprendizagem matemática de alunos da Educação de Jovens e Adultos (EJA). Levando em conta a imersão na cultura digital que a atual sociedade vivencia, o pesquisador se dedicou a estudar, investigar, observar e evidenciar as possíveis contribuições para o processo de aprendizagem de tarefas exploratórias investigativas de matemática permeadas pelas TICs, no âmbito da EJA. O estudo possui caráter qualitativo, interpretativo e participativo. Fundamentou-se teoricamente em autores que realizaram pesquisas sobre os temas relacionados. A análise deste estudo teve um caráter interpretativo advindo das informações que emergiram das informações coletadas na pesquisa. Os resultados indicaram a contribuição do uso das tecnologias, em especial as TICs, no favorecimento do processo de ensino e aprendizagem de Matemática quando se propõe tarefas exploratórias investigativas em turmas da EJA. Espera-se que a pesquisa contribua na formação inicial e continuada de professores de Matemática e com o processo de ensino e aprendizagem dos alunos da EJA.

Palavras-chaves: Aprendizagem Matemática, Tecnologias, Educação de Jovens e Adultos.

\begin{abstract}
The present text contains the main results of a master research proposal that aim to investigate the potential use of technologies, in special the information and communication technology (ICTs), in the process of mathematics teaching for the Adult Basic Education (ABE). Taking the digital culture immersion of the current society into

\footnotetext{
${ }^{1}$ Mestre em Ensino de Ciências e Matemática pela Universidade Federal de Uberlândia - UFU. Atua como professor de Matemática na rede municipal de Uberlândia - MG - brunotborba@gmail.com.

2 Doutora em Educação Matemática pela Universidade Estadual de Campinas - Unicamp. Atua como professora e orientadora do Programa Pós-graduação em Ensino de Ciências e Matemática da Universidade Federal de Uberlândia - UFU - mtmfreitas@gmail.com.
} 
account, the authors dedicated to study, investigate, observe and highlight the possible contributions of exploratory and investigative mathematical tasks in the teaching process, permeated by ICTs, in the ABE context. The study has a qualitative, interpretive and participatory character, based theoretically in related researches. The analysis were based on information collected during the survey. The result showed the contributions of the applied technologies, in special the ICTs, that indicates the benefits of its usage in mathematics teaching and learning process when investigative and exploratory tasks are presented for ABE classes. It is expected that the present research contribute to initial and continuing professional development of mathematics teachers and with the teaching and learning process in the ABE.

Keywords: Mathematics Learning, Technologies, Adult Basic Education.

\section{1) Introdução}

Este Produto é fruto da dissertação de mestrado profissional do Programa de Pós-graduação em Ensino de Ciências e Matemática da Universidade Federal de Uberlândia, sob a orientação da professora Dra. Maria Teresa Menezes Freitas.

A pesquisa teve seu embasamento teórico nos estudos sobre as contribuições para o processo de aprendizagem de tarefas exploratórias investigativas de matemática, utilizando as tecnologias em sala de aula em turmas de Educação de Jovens e Adultos.

A abordagem metodologia teve caráter qualitativo, interpretativo e participativo, tomando como principal foco o acompanhamento e a análise da produção colaborativa de saberes discentes, oriundos do desenvolvimento de propostas de ensino computacionais.

O produto pretende oferecer à comunidade matemática propostas de ensino que possam contribuir para o desenvolvimento do pensamento matemático crítico dos alunos da Educação de Jovens e Adultos no processo de aprendizagem Matemática, além de instigar a reflexão sobre as possibilidades de aprimoramento nas relações de aprendizagem no âmbito da EJA.

Os resultados da pesquisa evidenciaram as potencialidades das tecnologias, em especial as Tecnologias da informação e Comunicação ao 
contribuir com o processo de ensino e aprendizagem de Matemática, aliando, neste contexto, tarefas exploratórias investigativas em turmas da Educação de Jovens e Adultos.

Avalia-se que a pesquisa tem potencial para contribuir tanto para a formação inicial quanto para a continuada de professores de Matemática, especialmente para aqueles que atuam ou atuarão no processo de ensino e aprendizagem dos alunos da Educação de Jovens e Adultos.

Ressalta-se que o produto aqui apresentado poderá sofrer alterações levando-se em conta que os alunos em cada turma apresentam desempenhos diferenciados fazendo surgir outros desdobramentos diferentes daqueles evidenciados durante a pesquisa.

\section{2) Apresentação do Produto Educacional}

Duas propostas de ensino foram planejadas, sendo que uma delas utilizava somente as Tecnologias da Informação e Comunicação e a outra conciliava as TICs com outro recurso pedagógico, o Espelho Plano.

Nas duas propostas de ensino, utilizou-se o blog e o e-mail, contudo, na proposta que explorava os conceitos de Área e Perímetro, também se fez uso do software PowerPoint instalado em computadores do laboratório da escola. $\mathrm{Na}$ proposta de Ângulo e Simetria, utilizou-se o software GeoGebra instalado nos computadores do laboratório e conciliou, para compor o processo de aquisição de conhecimentos, Espelhos Planos, quadro branco, caneta e papel.

Para o desenvolvimento/ação das propostas de ensino, a ambientação e manipulação das TICs utilizadas, como o uso dos instrumentos de coleta de informações da pesquisa, foram necessários quatro encontros ${ }^{3} \mathrm{em}$ momentos de aulas com os alunos de três turmas, sexto, sétimo e nono anos da EJA.

\footnotetext{
${ }^{3}$ Os horários das aulas aconteciam das $18 \mathrm{~h} 50 \mathrm{~min}$ às $22 \mathrm{~h} 10 \mathrm{~min}$ e, como as aulas de todas disciplinas eram sempre geminadas (ou seja, duas aulas seguidas), procurou-se denominar, nesta pesquisa, os momentos de aula como "encontro de matemática", sendo que cada encontro corresponde a duas aulas geminadas. Os encontros possuíam duração média de $1 \mathrm{~h} 30 \mathrm{~min}$.
} 
O desenvolvimento ocorreu no segundo e terceiro encontros com os alunos da EJA, com o intuito de melhor compreender a estruturação das propostas de ensino na referida pesquisa. A tabela abaixo apresenta os encontros ocorridos com seus respectivos momentos, que serão detalhados na sequência deste texto.

\begin{tabular}{|c|c|c|}
\hline ENCONTROS & DATAS (Encontros e Momentos) & $\begin{array}{l}\text { PROPOSTAS/ AÇÕES } \\
\text { DESENVOLVIDAS }\end{array}$ \\
\hline \multirow{2}{*}{$2{ }^{\circ}$ encontro } & $\begin{array}{l}\text { 6o Ano (08/03/2016 / 1ํ e } 2^{\circ} \text { momento), } \\
7^{\circ} \text { Ano (09/03/2016 / 1으 e } 2^{\circ} \text { momento) }\end{array}$ & $\begin{array}{l}\text { Atividades de Área e } \\
\text { Perímetro }\end{array}$ \\
\hline & 9ำ Ano (10/03/2016 / 1ำ ao 4ํ momento) & $\begin{array}{l}\text { Atividades de Simetria e } \\
\text { Ângulo }\end{array}$ \\
\hline \multirow{2}{*}{3 encontro } & 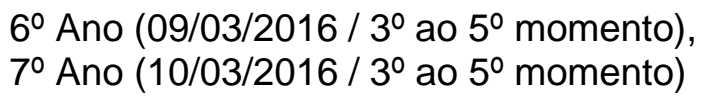 & $\begin{array}{l}\text { Atividades de Área e } \\
\text { Perímetro }\end{array}$ \\
\hline & 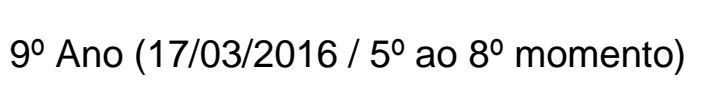 & $\begin{array}{l}\text { Atividades de Simetria e } \\
\text { Ângulo }\end{array}$ \\
\hline
\end{tabular}

O primeiro encontro com a turma na escola teve o intuito de apresentar esclarecimentos sobre as propostas de ensino que fariam parte da pesquisa e este encontro ocorreu no laboratório de informática da escola. A princípio, realizou-se um momento de familiarização com aquele ambiente, pois, na sala, havia alguns alunos que nunca tinham se sentado à frente de um computador, como também aqueles que mal conheciam o seu funcionamento.

Cada turma recebeu explicações do passo a passo do funcionamento do computador, bem como foi oferecido informações sobre o nome de cada parte do aparelho e o detalhamento de suas funções. Após o enfrentamento inicial, de superação do medo frente ao uso do computador, os discentes foram orientados para a criação de um e-mail pessoal do Gmail ${ }^{4}$.

O objetivo principal da criação deste e-mail justifica-se por ser esta a forma necessária para se acessar o blog desenvolvido para auxiliar nas propostas de ensino. Entretanto, a explicação não se ateve à criação de um e-mail, pois aconteceram também orientações de como utilizá-lo. Os alunos foram orientados

${ }^{4} \mathrm{~A}$ plataforma escolhida para hospedar o Blog foi a Blogger, que só aceita o Gmail como usuário, porque tanto o Blogger quanto o Gmail, pertencem a Google, por isso a exigência. 
sobre os passos para enviar, abrir e excluir um e-mail. A fim de verificar a compreensão de algumas etapas abordadas, solicitou-se que cada aluno enviasse um e-mail para o professor/pesquisador, e, posteriormente, os alunos deveriam enviar outra mensagem para um dos colegas de turma e/ou para a professora da turma.

Essa ação de troca de mensagens por e-mail contribuiu com a dinâmica da pesquisa, pois o professor pesquisador não precisou anotar os e-mails criados, tendo em vista que já os possuía em sua caixa de mensagens. Dessa forma, o professor pesquisador teve apenas que copiar e enviar os convites aos alunos para entrar no blog.

O blog criado foi intitulado "Aprendendo Matemática na EJA", com o seguinte endereço eletrônico (www.matematicaejaeseba.blogspot.com). Este blog foi dividido em três abas: aba "Início" que corresponde ao formulário eletrônico para todos responderem; na aba "Aula do $6^{\circ}$ e $7^{\circ}$ ano", disponibilizou-se o link para realização do download do arquivo do software escolhido para o desenvolvido da proposta de ensino para os referidos anos e a aba "Aula do $9^{\circ}$ Ano" também possuía o link para realização do download do arquivo do software escolhido para o desenvolvido da proposta da tarefa correspondente.

Como o blog, a princípio, fora criado para uso exclusivo dos alunos desta pesquisa, foi necessário, para se ter acesso ao blog, a criação de um usuário e senha. Após a defesa da dissertação de mestrado, o acesso foi disponibilizado ao público para que todos os professores possam usufruir de seu conteúdo, sem a necessidade de senha.

O usuário dos alunos foi definido como sendo o endereço eletrônico (email) e a senha seria a mesma senha do e-mail. Mas, para que esse processo ocorresse, foi necessário que o administrador do blog, no caso o professor pesquisador, enviasse um e-mail para cada aluno com o convite de acesso ao blog.

Esses convites foram enviados pelo professor/pesquisador, depois do primeiro encontro e às vésperas do segundo encontro, tentando garantir que 
esses convites não se perdessem ou fossem enviados para a lixeira da caixa de e-mail.

Antes do desenvolvimento das propostas de ensino, já no segundo encontro, o professor solicitou, em todas as turmas, que cada aluno acessasse seus e-mails pessoais e aceitasse o convite para acessar o blog. Em seguida, quando todos já haviam conseguido entrar no blog, solicitou-se a cada turma que selecionasse a aba que correspondesse a sua turma. Nesta aba, existia o link para download do arquivo que seria utilizado em suas respectivas tarefas/propostas de aula.

Sob a orientação do professor pesquisador, os alunos 'baixaram' esses arquivos que faziam referência a cada uma das tarefas detalhadas adiante.

\section{3) Detalhamento das propostas de ensino: Relevância e Potencial do produto educacional}

\section{Proposta de Área e Perímetro - Sexto e Sétimo Anos}

Optou-se, nesta proposta, por utilizar um recurso que os alunos já tinham domínio para que não se esbarrasse na burocracia de instalar um software e para que não se perdesse tantas aulas com orientação de como manipular o recurso.

A dinâmica escolhida foi fazer do PowerPoint um recurso pedagógico nas aulas de Matemática, transformando esse software de ferramenta para o contexto educacional.

Almejou-se, assim, que essa proposta de aula proporcionasse um ambiente investigativo aos alunos do sexto e sétimo anos da EJA, os quais poderiam atribuir características e significados próprios ao programa, de forma que desenvolvessem as definições e as relações de área e perímetro de uma forma interativa e criativa, tendo o PowerPoint como uma ferramenta computacional efetiva no processo de construção do conhecimento. 
Com o intuito de contribuir para a aprendizagem de conceitos de Geometria, optou-se por uma metodologia considerada adequada, almejando que os alunos atingissem os seguintes objetivos:

$>$ criar, manipular e estabelecer relações entre unidades de medida;

- perceber a necessidade de padronizar as unidades de medida de comprimento e área, por meio de situação real e da história da Matemática;

> reconhecer a aplicabilidade dos conteúdos abordados;

> investigar uma possível relação entre área e perímetro.

A proposta de ensino foi desenvolvida em cinco momentos.

\subsection{Primeiro Momento: Criar unidades de medida}

O objetivo principal desta etapa foi explicitar a necessidade de criar unidades de medida padrão.

A princípio, solicitou-se a criação de unidades de medida para medir a moldura de um determinado quadro (Figura 1) e o espaço que este quadro ocuparia na parede. Para a criação das unidades de medida, o aluno poderia utilizar tanto os recursos do software, como as formas e polígonos do próprio programa, quanto as imagens da galeria de imagens virtuais.

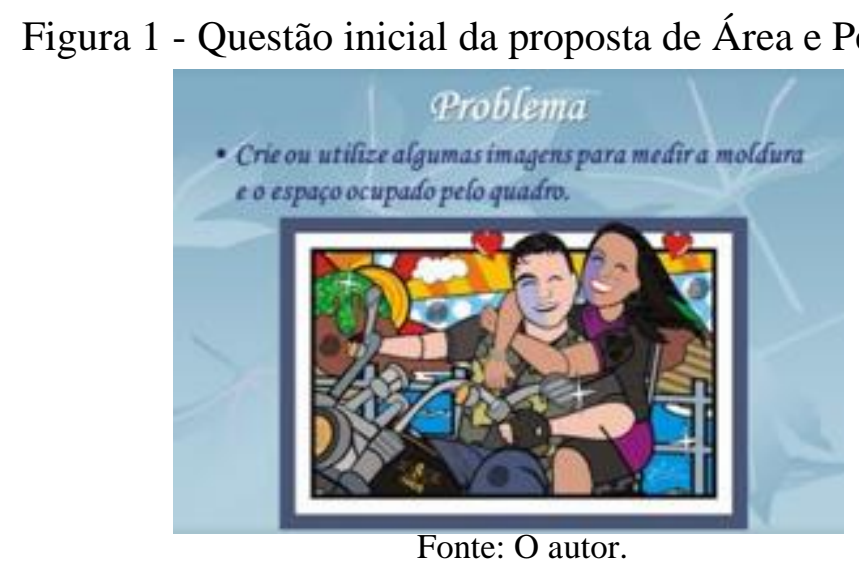

Em seguida, em diálogo e interação entre os colegas, os alunos foram questionados sobre as medidas do quadro e de sua moldura, e perceberam, 
assim, que suas unidades e suas medidas eram diferentes. O diálogo estabelecido apontou a necessidade da criação de unidades-padrão.

\subsection{Segundo Momento: História da Matemática}

Um breve contexto da história da Matemática foi apresentado neste momento mostrando a necessidade histórica de padronizar as unidades de medida, enfatizando a unidade de medida de comprimento.

Antes da apresentação das unidades de medida padronizadas, o professor/pesquisador comentou com a turma sobre as primeiras unidades de medida não padronizadas, que eram as partes do corpo humano, ressaltando que estas se alteravam de pessoa para pessoa, pois existem pessoas que são pequenas e outras que são grandes. Dessa forma, os alunos compreenderam que houve, no decorrer da história, uma necessidade de se padronizar medidas de comprimento.

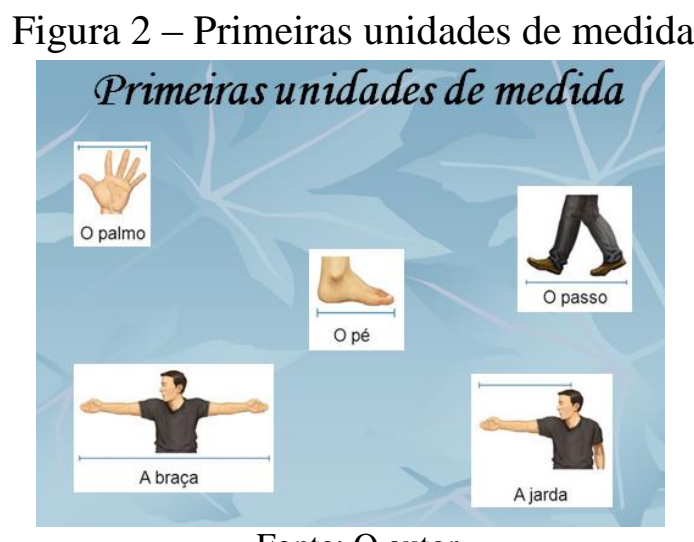

Fonte: $\mathrm{O}$ autor.

Em seguida, comentou-se com os alunos que uma tentativa de padronizar a unidade de medida se deu com a utilização das medidas de um único homem: o rei. Porém, com o crescimento do comércio, as confusões continuaram, pois cada país tinha o seu rei e suas medidas.

Silva (2010) confirma essa informação, ressaltando o sistema de unificação imposto pelo imperador romano Carlos Magno, no ano 809, que obteve maior 
sucesso e ficou conhecido pelos historiadores, pois esse sistema perdurou até a divisão do Império Carolíngio.

\begin{abstract}
Um exemplo interessante foi o padrão de unidade de comprimento proposto por Carlos Magno. Ele desejava naquela época, estabelecer um padrão universal e propôs, para isso, adotar o "Pé do Cristo", ou, mais precisamente, as marcas do pé de Cristo gravadas sobre o Santo Sudário, como padrão de unidade de comprimento. O valor corresponde a $31,23 \mathrm{~cm}$. Não se sabe exatamente por que, mas acabou-se adotando outro padrão. Fixou-se, na época, que o padrão de unidade de comprimento a ser adotado em todo o seu reino seria o "Pé do Rei", que correspondia a $32,84 \mathrm{~cm}$. (SILVA, 2010, p. 65)
\end{abstract}

Os esclarecimentos para os alunos continuaram, informando que, na França, em 1790, época da Revolução Francesa, a Academia de Ciências Francesa foi então encarregada de fixação das unidades-padrão, propondo um sistema totalmente novo e unificado para todo o território francês.

\begin{abstract}
A Academia pronunciou-se, então, pela adoção da fração de um arco de meridiano. Fixou-se que décima milionésima parte da quarta parte de um arco de meridiano terrestre, medido entre o Equador e o Polo Norte, seria adotada como unidade de medida linear, denominada metro. Estabeleceu-se então, que um arco de meridiano de aproximadamente 9,5 graus seria medido entre Dunkerque, na França, e Barcelona, na Espanha, e o resultado dessa medição seria usado como unidadepadrão para a nova unidade de medida linear (SILVA, 2010, p. 83).
\end{abstract}

Os alunos foram esclarecidos sobre os caminhos em que foi proposto 0 sistema métrico decimal, que não dependiam mais das medidas do corpo humano, ressaltando-se, assim, uma unidade de medida padrão para comprimento. O professor/pesquisador relatou, neste momento, que a opção se deu por utilização da décima milionésima parte da quarta parte de um arco de meridiano terrestre, chamando-a de metro. A palavra metro vem do grego métron e significa "o que mede". Uma das inovações dessa proposta foi a adoção do sistema de numeração decimal para o novo sistema de medidas.

Dessa maneira, os discentes puderam notar que, historicamente, o homem também teve a necessidade de padronizar as unidades de medida, mas tiveram dificuldade em padronizar as unidades-padrão de medida. 


\subsection{Terceiro Momento: Relacionar área e perímetro, sem definir os conceitos}

Este momento teve como objetivo investigar uma possível relação entre área e perímetro, sem definir conceitos. Para tanto, foi solicitado aos alunos que medissem as molduras e os espaços ocupados por três quadros retangulares diferentes, usando as mesmas unidades de medida. Após o momento de medição dos quadros, os alunos compararam as medidas, observando as regularidades, ou seja, o que as medidas apresentavam de comum e/ou de diferente.

Nesta etapa foram utilizadas unidades padronizadas não convencionais para a medição. Estas unidades não padronizadas foram criadas pelo professor pesquisador e dispostas em uma "caixa de ferramentas" no PowerPoint. Para a unidade linear, foi utilizado a unidade que foi denominada de "pesinho" e para a unidade de área foi utilizada a unidade denominada por "bloquinho", conforme se pode observar nas figuras 3 e 4 .

Figura 4 - Bloquinho

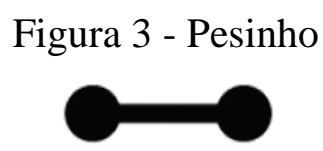

Fonte: $\mathrm{O}$ autor.

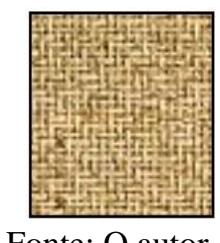

Fonte: $\mathrm{O}$ autor.

Nas questões propostas, o professor instigou os alunos a medirem a área e o perímetro de retângulos e atentar para o que acontece com o perímetro quando os retângulos possuem a mesma área. Depois, houve oportunidade de verificar o que acontece com a área, tendo retângulos de mesmo perímetro.

$\mathrm{Na}$ sequência, apresentou-se as questões 1, 2 e 3, com seus referidos quadros, os quais os alunos foram solicitados a medir e a comparar.

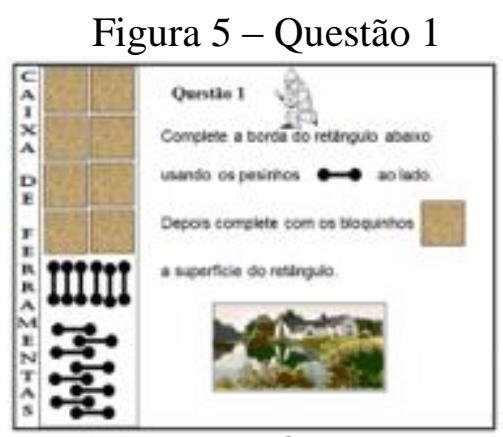

Fonte: $\mathrm{O}$ autor.
Figura 6 - Questão 2

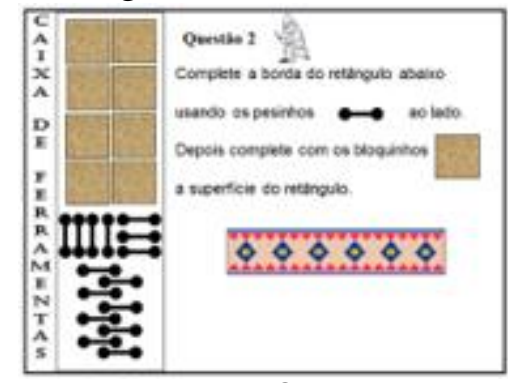

Fonte: $\mathrm{O}$ autor. 


\section{Figura 7 - Questão 3}

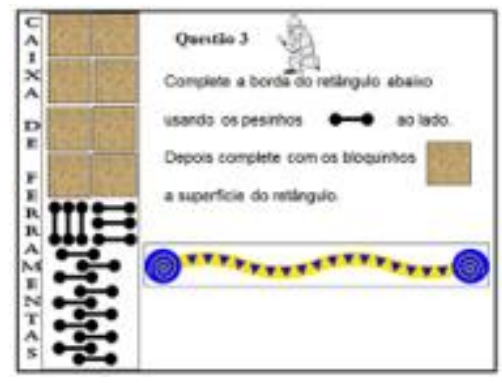

Fonte: O autor.

Após cada questão, os alunos foram solicitados a responder em um dos slides do PowerPoint, quantos 'pesinhos' e quantos 'bloquinhos' seriam necessários para medir a moldura e o espaço ocupado de cada quadro, respectivamente.

No final da segunda questão, os alunos já começaram a relatar o que percebiam ao analisar as medidas da questão 1 e 2. De maneira análoga, ao final da questão 3 , os alunos relataram o que percebiam ao analisar as medidas da questão 1 e 3.

\subsection{Quarto Momento: Relacionar e formalizar os conceitos}

Neste momento formalizou-se esses conceitos de forma sistematizada enquanto conhecimentos científicos e, posteriormente, em conjunto com a turma, foram analisados os resultados da atividade 1 e da atividade 2, relacionando os resultados. Depois desta etapa, os alunos analisaram a atividade $1 \mathrm{e}$ a atividade 3 , também relacionando seus resultados.

Por último, já utilizando as definições e os resultados das questões anteriores, os alunos realizaram uma comparação entre a área e o perímetro dos quadros de formato retangular.

\subsection{Quinto Momento: Questões investigativas referentes a área e perímetro}


Neste momento duas questões investigativas que apresentavam situações reais que exploravam os conceitos de área e perímetro foram apresentadas.

01. Se uma tecelã quer dobrar o tamanho do seu tapete, vai ser necessário dobrar o arremate em volta dele?

Figura 8 - Questão investigativa 1

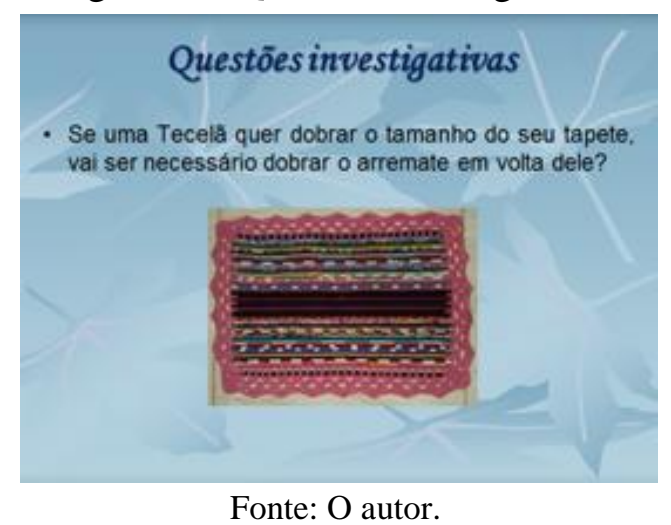

Essa questão investigativa 1, buscou explorar uma situação real, que envolve uma relação entre a medida da área e a medida do perímetro de um tapete, ou seja, os alunos teriam que investigar se ao dobrar a área do tapete, o arremate que, neste caso, representa a unidade de medida de perímetro, também iria dobrar de comprimento.

02. Sabemos que os retângulos das questões 1 e 3 possuem mesma área. Se eles fossem terrenos, qual deles você preferiria comprar, o terreno da questão 1 ou o terreno da questão 3 ou tanto faz?

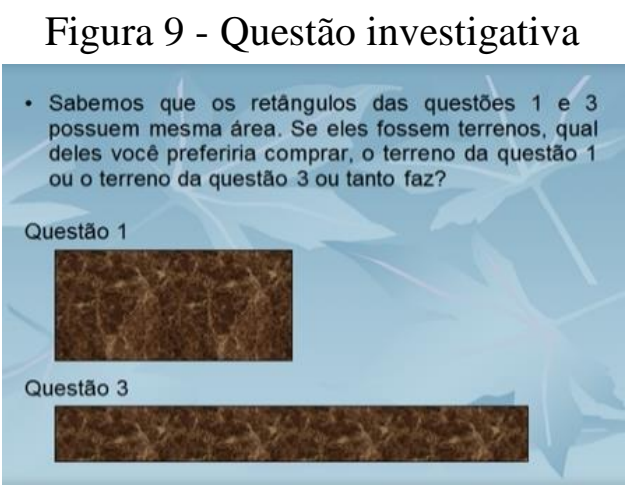

Fonte: $\mathrm{O}$ autor.

$\mathrm{Na}$ tarefa investigativa da questão 2 buscou-se instigar os alunos a realizarem uma análise sobre a vantagem na compra de terrenos, relacionando 
dois terrenos de mesma área, mas com perímetros diferentes. Essa comparação provém de uma relação já estabelecida no momento anterior.

\section{Proposta de Simetria e Ângulo - Nono Ano}

Na busca de utilização de recursos tecnológicos, esta proposta de ensino buscou conciliar o uso das TICs, como também dos Espelhos Planos. Dessa maneira, desenvolveu-se essa proposta na intenção de explorar conceitos geométricos na EJA.

Acreditando-se na relevância da Geometria na Educação de Jovens e Adultos, procurou-se explorar o máximo de conceitos possíveis, sem perder a qualidade de ensino, tendo como foco os conceitos de Simetria e de Ângulo, mas realizando conexões com: rotação, eixos de simetria, paralelismo, representação simbólica de um ângulo, medição dos ângulos, classificações dos ângulos, soma dos ângulos internos de um triângulo, classificações dos triângulos quanto aos ângulos, ângulo central do polígono e nomenclatura dos polígonos.

Acredita-se que, para o aluno aprender Matemática com significado, seja fundamental a aprendizagem com compreensão, atribuindo sentido ao que aprende. Para tal, considera-se importante que o aluno saiba o porquê das coisas, e não simplesmente memorize conceitos e propriedades, levando em conta a valorização do conhecimento prévio do aluno instigando-o a pensar logicamente, relacionando ideias, descobrindo regularidades e padrões, estimulando sua curiosidade, seu espírito de investigação e a sua criatividade.

Assim, a expectativa desta proposta era que os alunos do nono ano pudessem:

$>$ manipular os objetos didáticos e averiguar as simetrias;

$>$ reconhecer as diferentes classificações simétricas, com seus possíveis eixos de simetria;

$>$ conceituar, medir e classificar os ângulos;

> somar os ângulos internos de um triângulo, classificar os triângulos quanto 
aos ângulos;

> investigar uma possível relação entre os ângulos centrais e os polígonos.

$>$ criar e observar os possíveis polígonos, formas geométricas.

Com o intuito de atingir esses objetivos, a proposta foi fragmentada em oito momentos, sendo quatro momentos para cada encontro.

\subsection{Primeiro Momento: Explorar as reflexões}

Antes da abordagem de qualquer definição foi proposto um desafio de se colocar um espelho plano simples em determinado lugar da 5'Figura 10' para tentar obter as imagens da 'Figura 11' e da 'Figura 12'.

Figura 10 - Burro

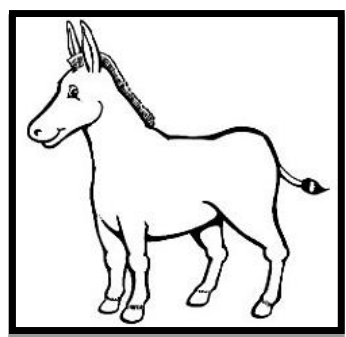

Fonte: Colorir Desenhos.
Figura 11 - Reflexo 1 do burro

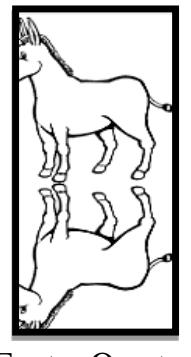

Fonte: $\mathrm{O}$ autor.
Figura 12 - Reflexo 2 do burro

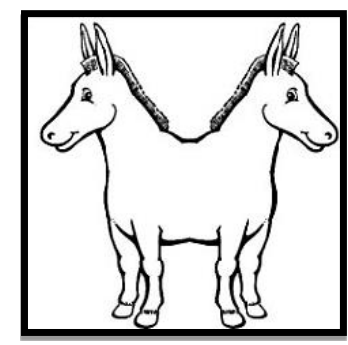

Fonte: $\mathrm{O}$ autor.

Esse desafio foi proposto com o intuito de oportunizar circunstâncias adequadas e favoráveis para a prática de reconhecimento de figuras diferentes e seleção de partes de figuras congruentes a outras. A proposta foi propícia para a observação de propriedades de figuras geométricas e a exploração do conceito de simetria.

Em seguida, foram dispostas figuras e o professor/pesquisador solicitou à turma que colocasse o espelho plano onde se encontrava o(s) eixo(s) de simetria, em busca de figuras com estrutura simétrica e contagem dos eixos de simetria. $A$ seguir, apresenta-se algumas das imagens ${ }^{6}$ utilizadas.

\footnotetext{
${ }^{5}\langle$ http://colorirdesenhos.com/files/styles/slideshow_vertical/public/desenhos/cavalo4.jpg?itok=BSllsQMD>

${ }^{6}$ Fontes: Borboleta - ClipartAll - <http://img.clipartall.com/butterfly-20clipart-20black-20and-20whiteblack-and-white-butterfly-clipart-250_190.jpg >
} 
Figura 13 - Borboleta

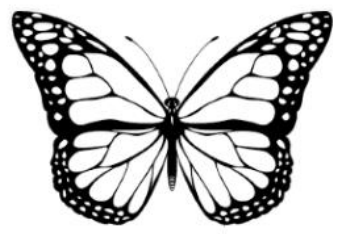

Fonte: ClipartAll
Figura 14 - Cálice

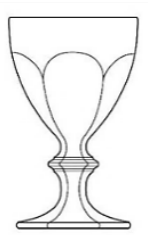

Fonte: Replacements Ltda
Figura 15 - Estrela

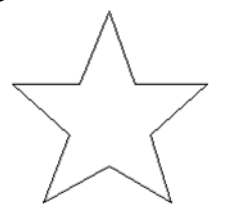

Fonte: ClipartAll
Figura $16-$ Floco de neve

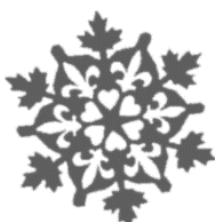

Fonte: Blog Update Info

Esta dinâmica teve o intuito de classificar o tipo de simetria, segundo o número de eixos, como simetria axial ou bilateral e simetria de rotação ou central. Assim, conseguiu-se explicitar e abordar os conceitos de reflexão, rotação e de translação.

\subsection{Segundo Momento: Verificar paralelismo e reflexões sucessivas}

O segundo momento incluiu o trabalho com dois espelhos planos $e$ paralelos. Solicitou-se aos alunos que colocassem as figuras geométricas e/ou imagens entre os espelhos e verificassem a reflexão nos sentidos dos espelhos.

Figura 17 - Imagem entre os espelhos paralelos
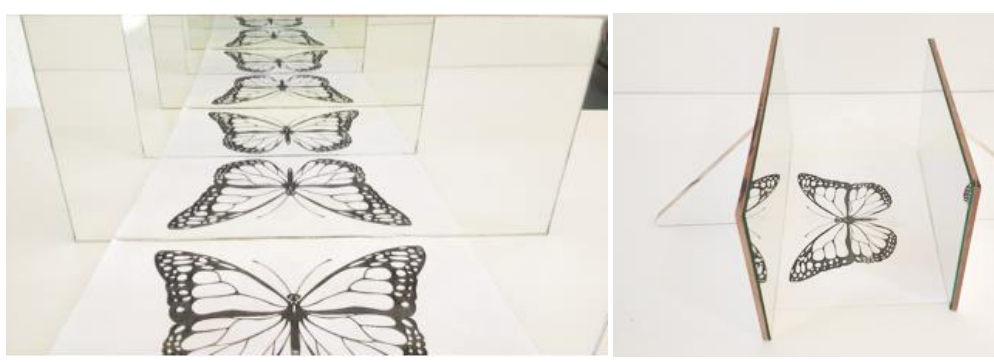

Fonte: $\mathrm{O}$ autor.

Dessa forma, seria possível observar as reflexões sucessivas dispostas nos espelhos, abordando os conceitos de translação e paralelismo. Quando

Cálice - Replacements Ltda -

<https://images.replacements.com/images/images2/crystal/C/P0000156298S0003T2.jpg>

Estrela - ClipartAll - <http://img.clipartall.com/bold-star-outline-clip-art-star-outline-clipart-400_393.jpg >

Floco de Neve - Blog Update Info - <http://3.bp.blogspot.com/-

VqxS0ZpzxcI/UljVF9wZbpI/AAAAAAAAMzM/H2vBvAUPzDM/s1600/Flocos+de+Neve+(6).png> 
dispostos os espelhos da forma anunciada é possível notar um número infinito de imagens formadas entre os mesmos, como pôde ser visualizado acima.

\subsection{Terceiro Momento: Representar a simetria}

Para a representação do que se compreendeu sobre Simetria, no terceiro momento, utilizou-se o software GeoGebra, fazendo uso da malha quadriculada e os eixos cartesianos do programa, como eixos de simetria. Solicitou-se aos alunos que inserissem pontos do lado esquerdo do eixo vertical, alocando-os na malha quadriculada.

Em seguida, tomando o eixo vertical como eixo de simetria desses pontos, foi solicitado aos alunos que inserissem seus pontos simétricos em relação a esse eixo. Posteriormente, o mesmo procedimento de inserção de pontos simétricos foi solicitado, mas com relação ao eixo horizontal, conforme ilustra a figura abaixo.

Figura 18 - Representação de pontos simétricos no GeoGebra

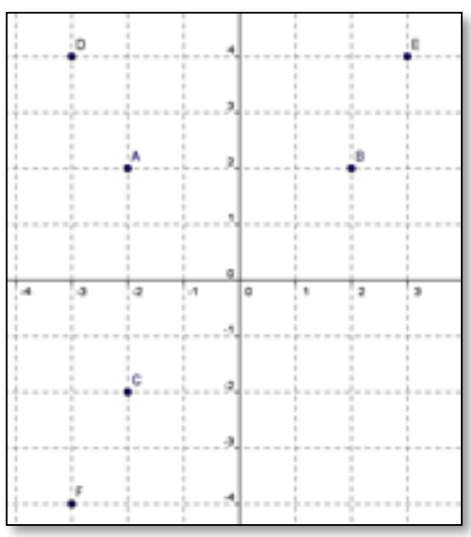

Fonte: $\mathrm{O}$ autor.

Esta proposta teve como intuito a construção e a representação simétrica de pontos com relação aos eixos cartesianos, utilizando esses eixos apenas para representar os pontos simétricos, pois não foi abordado nem informado detalhes sobre o plano cartesiano e as coordenadas cartesianas. 


\subsection{Quarto Momento: Conceituar, medir e classificar os ângulos}

No quarto momento, o professor pesquisador solicitou aos alunos que rotacionassem sobre a mesa do laboratório de informática, dois espelhos planos de forma articulada, ou seja, um espelho encostado no outro espelho, para explorar e construir o conceito de ângulo, explorando também as regiões entre os espelhos.

Depois de evidenciar o conceito de ângulo, utilizando apenas os espelhos planos articulados sobre o transferidor confeccionado em uma cartolina, solicitouse aos alunos que medissem o ângulo de abertura entre os espelhos, utilizando o transferidor posicionado abaixo dos espelhos.

Figura 19 - Representação dos ângulos utilizando os espelhos

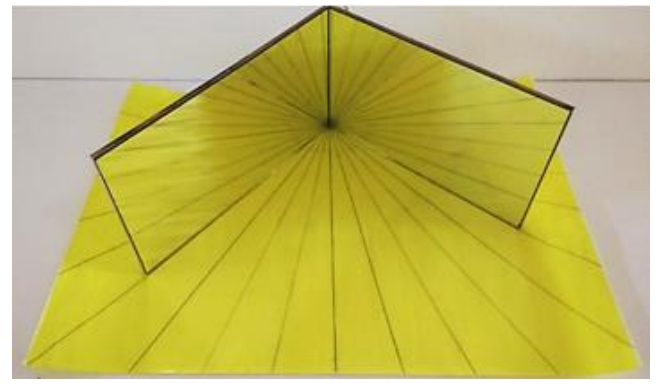

Fonte: $\mathrm{O}$ autor

Após esse processo de aprender a medir os ângulos, utilizando o transferidor, foram esclarecidos detalhes sobre as classificações de ângulos (reto, raso, obtuso e agudo).

Toda proposta do quarto momento teve a intenção de conceituar, medir e classificar os ângulos, encerrando, assim, o segundo encontro.

\subsection{Quinto Momento: Exemplos práticos de ângulos}

Ao iniciar o terceiro encontro com a turma, o professor pesquisador deu início ao quinto momento, exemplificando situações reais nas quais o ângulo poderia ser notado e utilizado como ferramenta na profissão, esporte, lazer e no 
cotidiano. Para tanto, utilizou-se, além do computador e do PowerPoint, o datashow como ferramenta para ilustrar alguns exemplos práticos.

$\checkmark \mathrm{Na}$ construção civil, utiliza-se o prumo e o nível de bolha, respectivamente, para nivelamentos verticais de distância maiores, como verificar se as paredes estão ortogonais ao chão e para nivelamentos horizontais de pequenas distâncias, por exemplo, para colocação de uma prateleira.

$\checkmark$ No skate, com os movimentos e suas respectivas nomenclaturas $360^{\circ}, 720^{\circ}$ e $180^{\circ}$.

$\checkmark$ Nas residências, ao lavar o quintal ou aguar as plantas, o esguicho de água atinge determinada distância conforme inclinação do bico da mangueira.

$\checkmark$ Na guerra, o alcance máximo das bolas de canhões dependia da inclinação máxima dos canhões. Atualmente, os mísseis ainda utilizam os ângulos para ajustar o alvo e ajustar a trajetória.

$\checkmark$ Nos esportes, como o lançamento de dardos ou salto em distância, também utilizam o ângulo de inclinação ideal para o salto ou lançamento, como um dos fatos determinantes para atingir a maior distância.

$\checkmark$ Na musculação, ao realizar as atividades físicas em alguns aparelhos, conforme o aumento da declinação ou inclinação de determinados aparelhos, que são medidos em graus, transfere-se o enfoque muscular para partes diferentes da musculatura.

$\checkmark$ A legislação ambiental brasileira proíbe o desmate e o plantio em encostas com declividade maior que $45^{\circ}$.

$\checkmark$ A sombra é a ausência de luz, devido os raios que não atingiram o solo, mas seu tamanho depende do ângulo que o raio limite faz com o chão, quando esse ângulo é grande tem sobra pequena, já quando o ângulo é pequeno tem sombra grande.

$\checkmark \mathrm{Na}$ natureza, as corujas têm na disposição frontal dos olhos, apenas $50^{\circ}$ de ângulo de observação. Entretanto a natureza compensou tal limitação, com a versatilidade das vértebras do pescoço, tornando-as capazes de virar a cabeça num ângulo de 270², conseguindo olhar em todas as direções. Já o homem com a cabeça parada consegue observar $180^{\circ}$ a sua volta.

$\checkmark$ ângulo de visão humano altera conforme a distância dos olhos ao objeto observado, quanto mais afastado do objeto, menor o ângulo de visão, quanto mais aproximado do objeto, maior o ângulo de visão.

Esse momento foi planejado tendo como aspiração conseguir interações entre os alunos, o professor pesquisador e os colegas de turma, partilhando suas opiniões e experiências frente aos ângulos exemplificados.

\subsection{Sexto Momento: Soma dos ângulos internos de um triângulo e Classificação dos triângulos quanto aos seus ângulos}

No sexto momento, foi utilizado o arquivo do software GeoGebra 'baixado' do blog que possui um campo de futebol de plano de fundo, três pontos inseridos, 
dois na trave no gol e um representando o jogador de futebol Messi, também já referenciado o ângulo de visão do jogador em relação as traves do gol.

Foi solicitado aos discentes que movimentassem o jogador, arrastando o ponto que o representa em todas as direções do campo e, cuidadosamente, observar o que acontece com a medida deste ângulo de visão.

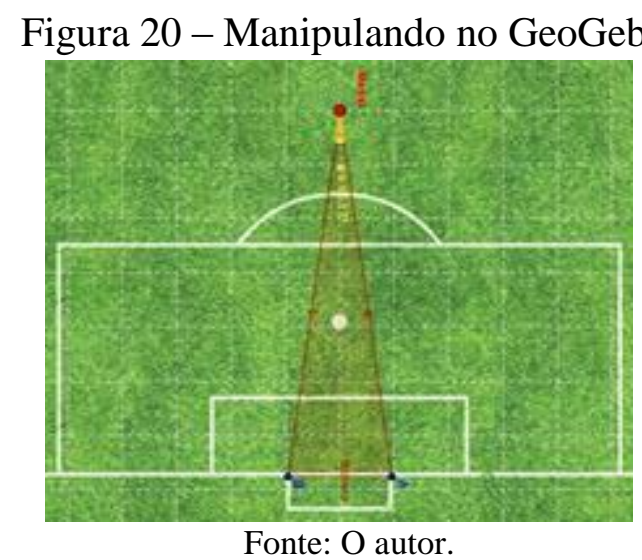

Posteriormente, ainda com a tela disposta no arquivo disponibilizado no blog, atentou-se para o triângulo construído pelo ponto do jogador e os pontos da trave, e, com a ajuda do software, os alunos foram orientados a medirem mais um dos ângulos do triângulo que havia sido formado. Em seguida, após a construção de um triângulo em folha de papel sulfite, mostrou-se, experimentalmente, que a soma dos ângulos internos de qualquer triângulo é $180^{\circ}$. A seguir, apresenta-se as ilustrações das imagens ${ }^{7}$, detalhando os passos realizados.

Figura 21 - Mostra experimental "Soma dos ângulos internos de um triângulo"

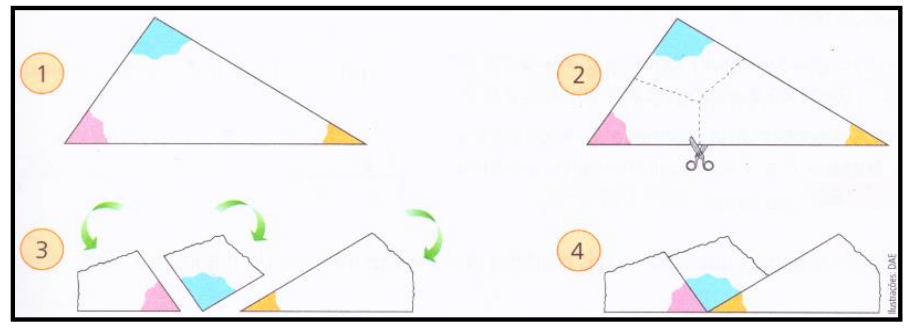

Fonte: ANDRINI, VASCONCELOS, 2012.

\footnotetext{
${ }^{7}$ Fonte da imagem: ANDRINI, Álvaro; VASCONCELLOS, Maria José. Coleção Praticando Matemática:

$8^{\circ}$ Ano. 3 ed. São Paulo: Editora do Brasil, 2012.
} 
Assim, após terem conhecimento do resultado da soma dos ângulos internos de um triângulo, solicitou-se aos alunos que, com auxílio da calculadora digital do computador ou do celular, calculassem a medida do terceiro ângulo e depois conferissem suas respostas por meio do software GeoGebra, registrando a medida desse terceiro ângulo no programa.

Nesse mesmo sentido, almejou-se explorar as classificações dos triângulos quanto aos seus ângulos (acutângulo, obtusângulo e retângulo), utilizando o triângulo ilustrado no GeoGebra.

\subsection{Sétimo Momento: Representação simbólica dos ângulos}

Para retratar a representação simbólica dos ângulos, utilizou-se uma apresentação projetada no datashow do laboratório de informática, mostrando as nomenclaturas utilizadas pelo ângulo, como também sua composição, como o vértice e os lados, desenvolvendo o sétimo momento.

Figura 22 - Representação simbólica de um ângulo

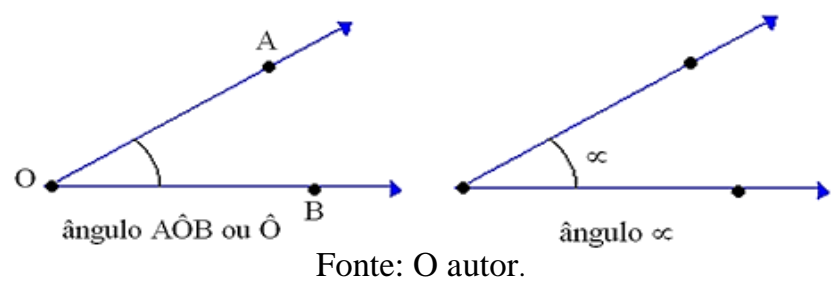

\subsection{Oitavo Momento: Construir polígonos}

O oitavo e último momento da proposta, novamente incluiu o trabalho com dois espelhos planos de forma articulada, com um transferidor já desenhado em uma cartolina. Solicitou-se aos alunos que rotacionassem os espelhos sobre o transferidor, conferindo os possíveis polígonos que seriam construídos, relacionando-os com o ângulo de abertura entre os espelhos.

Para uma melhor visualização, colocou-se um papel sulfite entre os dois espelhos de maneira que o objeto e os espelhos formassem um polígono. Assim, 
foi solicitado aos alunos que relacionassem a medida do ângulo central dos polígonos construídos e o número de lados do respectivo polígono.

A seguir, as ilustrações de algumas visualizações

Figura $23-120^{\circ} / 3$ lados

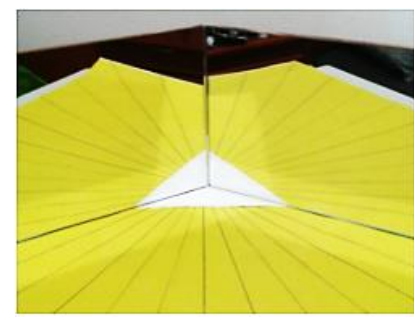

Fonte: $\mathrm{O}$ autor.
Figura $24-90^{\circ} / 4$ lados

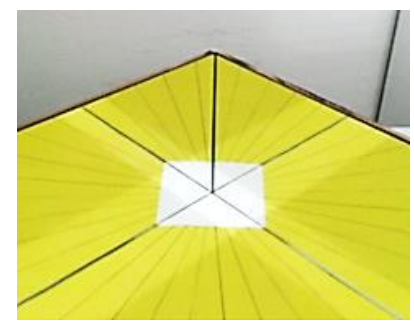

Fonte: $\mathrm{O}$ autor.
Figura $25-36^{\circ} / 10$ lados

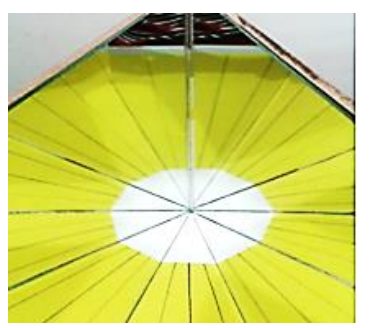

Fonte: $\mathrm{O}$ autor.

Ao desenvolver essa parte da proposta de ensino, esperou-se que ao visualizar os padrões simétricos para obtenção de polígonos, o professor pudesse retomar os conceitos de ângulo, reflexão e rotação.

\section{4) Considerações Finais}

Para encerrar este texto, que apresenta o produto associado ao desenvolvimento de uma pesquisa, espera-se que os leitores se sintam convidados e instigados a realizar a leitura na íntegra da dissertação que deu origem ao produto apresentado. A leitura do texto da dissertação possibilitará ao leitor vislumbrar os resultados obtidos pelos discentes participantes da pesquisa, observando as contribuições pedagógicas das tecnologias no processo de ensino e aprendizagem da Educação de Jovens e Adultos.

\section{5) Referências}

SILVA, I.. História dos Pesos e Medidas. 2. ed. São Carlos: Editora da Universidade Federal de São Carlos, 2010. 